$12 / 10^{2} \cdot 95950$

UCRL-ID-120596

\title{
Photoproduction of Tritium
}

\author{
J. A. Becker
}

J. D. Anderson

M. S. Weiss

March 23, 1995

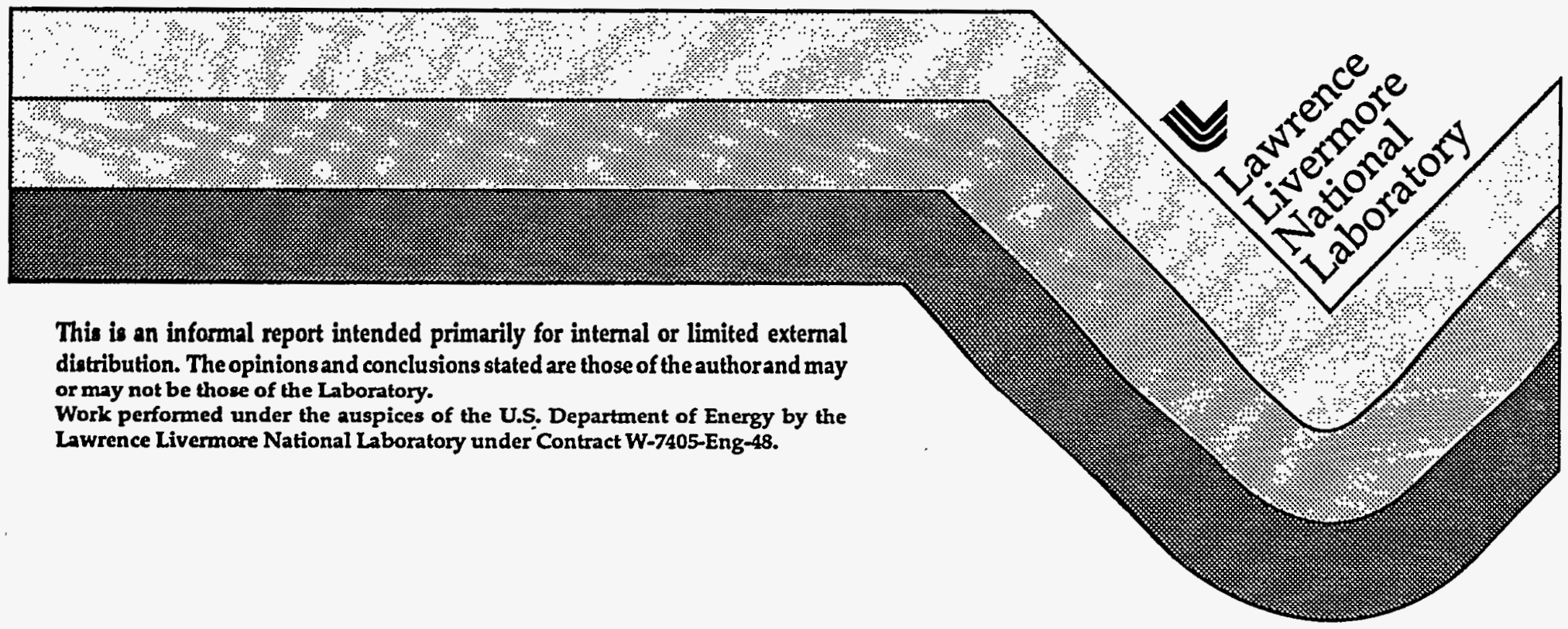




\section{DISCLAIMER}

This document was prepared 25 an account of work sponsored by an agency of the United States Government. Neither the United States Government nor the University of California nor any of their employees, makes any warranty, express or implied, or assumes any legal liability or responsibility for the accuracy, completeness, or usefulness of any information, apparatus, product, or process disclosed, or represents that its use would not infringe privately owned rights. Reference herein to any specific commercial products, process, or service by trade name, trademark, manufacturer, or otherwise, does not necessarily constitute or imply its endorsement, recommendation, or favoring by the United States Government or the University of Calfornia. The views and opinions of authors expressed herein do not necessarily state or reflect those of the United States Government or the University of California, and shall not be used for advertising or product endorsement purposes.

This report has been reproduced directly from the best available copy.

Avallable to DOE and DOE contrnctors from the Onfice of Scientific and Technical Information P.O. Box 62, Oak Ridge, TN 37831

Prices available from (615) 576-8401, FTS 626-8401

Available to the public from the

National Technical Information Service

U.S. Department of Commerce

5285 Port Royal Rd.

Springfield, VA 22161 


\section{DISCLAIMER}

Portions of this document may be illegible in electronic image products. Images are produced from the best available original document. 


\title{
Photoproduction of Tritium
}

\author{
J. A. Becker, J. D. Anderson, and M. S. Weiss \\ Lawrence Livermore National Laboratory \\ Livermore, California 94550
}

March 23, 1995

\section{Executive Summary}

Irradiation of ${ }^{7} \mathrm{Li}$ by low-energy photons produces tritium $\left({ }^{3} \mathrm{H}\right)$ via the photodisintegration process. Waste heat from the ${ }^{7} \mathrm{Li}$ target can be extracted and used for the direct generation of electricity. Other advantages include: negligible residual radioactivity, simple target technology, small low-energy electron accelerators for bremsstrahlung production (the photon source), developed liquid metal technology, modularity, simple extraction of ${ }^{3} \mathrm{H}$ from a recirculating ${ }^{7} \mathrm{Li}$ target, abundant supply of ${ }^{7} \mathrm{Li}$, and straightforward target-acceleratorbremsstrahlung converter interface.

A schematic plant characterized by very low risk is described, and a figure-of-merit is obtained. Electrons accelerated to low energies strike a high $\mathrm{Z}$ target, producing bremsstrahlung with high efficiency. The bremsstrahlung strikes a liquid ${ }^{7} \mathrm{Li}$ target. The competition between atomic and nuclear interactions takes place in a photon energy region where the cross section for atomic processes is at a minimum while the nuclear cross section is high. The major atomic process, Compton scattering, creates so little energy loss that the photon can be reused for photodisintegration. Liquid metal technology was developed for the breeder reactor program. ${ }^{7} \mathrm{Li}$ is available and abundant. The interface between accelerator, bremsstrahlung converter, and the ${ }^{7} \mathrm{Li}$ target does not require development. Low-energy, highefficiency electron accelerators are available commercially. The process does not produce long term radioactivity in the sense of fission or spallation products. Liquid ${ }^{7} \mathrm{Li}$ is recirculated by a pump. Tritium is extracted, and waste heat is recycled to energy in a heat exchanger or the magnetohydrodynamic pro-

cess during recirculation.

The figure-of-merit for ${ }^{3} \mathrm{H}$ production for this schematic plant expressed as grams of ${ }^{3} \mathrm{H}$ produced per MegaWatt year is:

$$
N_{T} \approx 2.08 \mathrm{~g} /(\mathrm{MW} \mathrm{y}) \text {. }
$$

\section{Introduction}

${ }^{3} \mathrm{H}$ (Tritium) is required for maintenance of nuclear weapons in the stockpile. The National Defense need for ${ }^{3} \mathrm{H}$ was historically met by the Savannah River Facility. This facility is no longer safe for operation. ${ }^{3} \mathrm{H}$ decays with a mean lifetime $\tau=17.8 \mathrm{y}$, and therefore new methods of ${ }^{3} \mathrm{H}$ production are required to meet US military requirements. Nonproliferation issues are also of concern when discussing tritium production.

\section{$2.1 \quad A P T$}

Accelerator production of tritium (APT) has been proposed using high current and high energy proton accelerators [LA-APT-4]. Protons accelerated to $\approx 1$ $\mathrm{GeV}$ strike a spallation target surrounded by a neutron multiplier blanket. The spallation neutrons are moderated in the target assembly and are captured in ${ }^{3} \mathrm{He}$ channels located within the target assembly. ${ }^{3} \mathrm{H}$ is produced by the ${ }^{3} \mathrm{He}(\mathrm{n}, \mathrm{p}){ }^{3} \mathrm{H}$ reaction. Characteristics of this method are:

- Target assemblies with massive amounts of residual radioactivity in the form of spallation productions

- Technical advances in accelerator design are required 
- Large and powerful accelerator(s) with devoted large $(\approx 500 \mathrm{MW})$ power stations.

\section{$3 \quad \mathrm{PPT}$}

Alternative methods for large scale ${ }^{3} \mathrm{H}$ production need to be considered. ${ }^{3} \mathrm{H}$ can be produced directly in low energy nuclear reactions. Irradiation of ${ }^{7} \mathrm{Li}$ by low energy photons produces ${ }^{3} \mathrm{H}$ via the photodisintegration process (PhotoProduction of Tritium, PPT):

$$
{ }^{7} \mathrm{Li}(\gamma, \alpha){ }^{3} \mathrm{H}, \quad Q=-2.46 \mathrm{MeV}
$$

Conceptually, a PPT facility design is straight forward: electrons accelerated to $E_{e} \approx 12$ $\mathrm{MeV}$ by a high current $\mathrm{CW}$ linac strike a high$\mathrm{Z}$ bremsstrahlung converter such as $\mathrm{Ta}$. The bremsstrahlung, which is forward directed, strikes a target assembly of ${ }^{7} \mathrm{Li}$. ${ }^{3} \mathrm{H}$ is produced via the $\gamma, \alpha$ reaction above. The ${ }^{3} \mathrm{H}$ is extracted from a recirculating ${ }^{7} \mathrm{Li}$ target, and waste heat is reclaimed for electricity. A schematic of the conceptual design discussed above is given in Fig. 1.
A - Accelerator
T - Tritium
B - Bremsstrahlung
P - Pump
H - Heat Exchanger

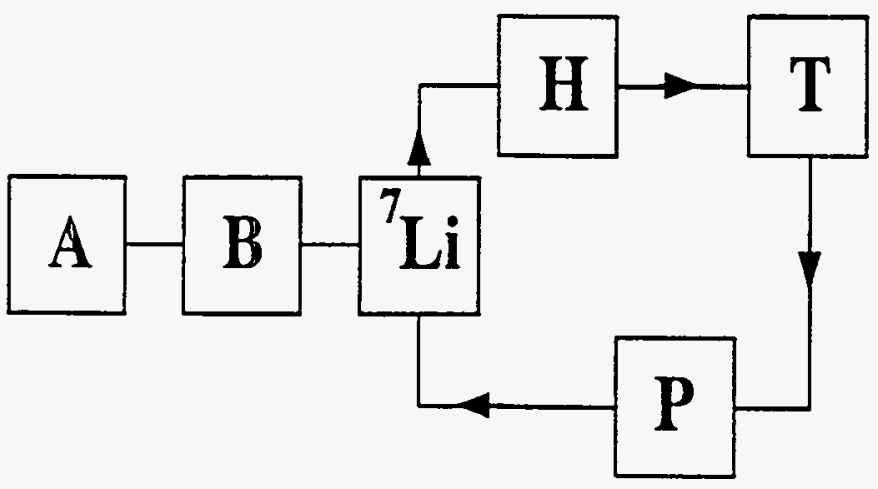

Figure 1: Conceptual schematic of ${ }^{3} \mathrm{H}$ production by photodisintegration of ${ }^{7} \mathrm{Li}$.

Risk associated with this process is low:

- Technical risk is low since no technical advances are required
Table 1: Symbols and units.

\begin{tabular}{ll}
\hline \hline Symbol & Definitions \\
\hline$N_{T}$ & number of ${ }^{3} \mathrm{H}$ atoms produced \\
$i$ & incident electron current \\
$\Phi_{e}$ & incident electron flux \\
$E_{e}$ & incident electron energy \\
$\epsilon_{\text {brems }}$ & bremsstrahlung conversion efficiency \\
$\epsilon_{\gamma}$ & bremsstrahlung fraction producing ${ }^{3} \mathrm{H}$ \\
$\sigma_{T}$ & nuclear cross section \\
$L$ & ${ }^{7} \mathrm{Li}$ assembly length \\
$\mu_{\text {pair }}$ & pair production coefficient \\
$N_{0}$ & Avogadro Number \\
$\mathrm{a}$ & ampere \\
$\mathrm{h}$ & hour \\
$\mathrm{y}$ & year \\
$\mathrm{g}$ & grams \\
$\mathrm{MW}$ & MegaWatt \\
\hline \hline
\end{tabular}

- ES \& $\mathrm{H}$ risk is low. The main residual radioactivity is $8 \mathrm{~h}^{180} \mathrm{Ta}$ which is localized in the converter. The main problem appears to be at the ${ }^{7} \mathrm{Li}$-bremsstrahlung interface. The ${ }^{7} \mathrm{Li}$ assembly must be kept from water.

This appears to us to be an alternative ${ }^{3} \mathrm{H}$ production method worth considering. Although the (electrical) cost per gram is larger than the APT value, PPT has distinct advantages.

\section{Figure-of-Merit}

This section of this paper presents numerical details of a simplified calculation for the number of ${ }^{3} \mathrm{H}$ atoms produced per ampere-year of incident electrons in this schematic arrangement. The production rate is also presented in grams per MegaWattyear for a useful figure-of-merit. The number of ${ }^{3} \mathrm{H}$ atoms is given by:

$$
N_{T}=\Phi_{e} \times N_{7_{L i}} \times \sigma_{T}
$$

\subsection{Definitions}

The meaning of symbols and units used in this document is given in Table 1. 


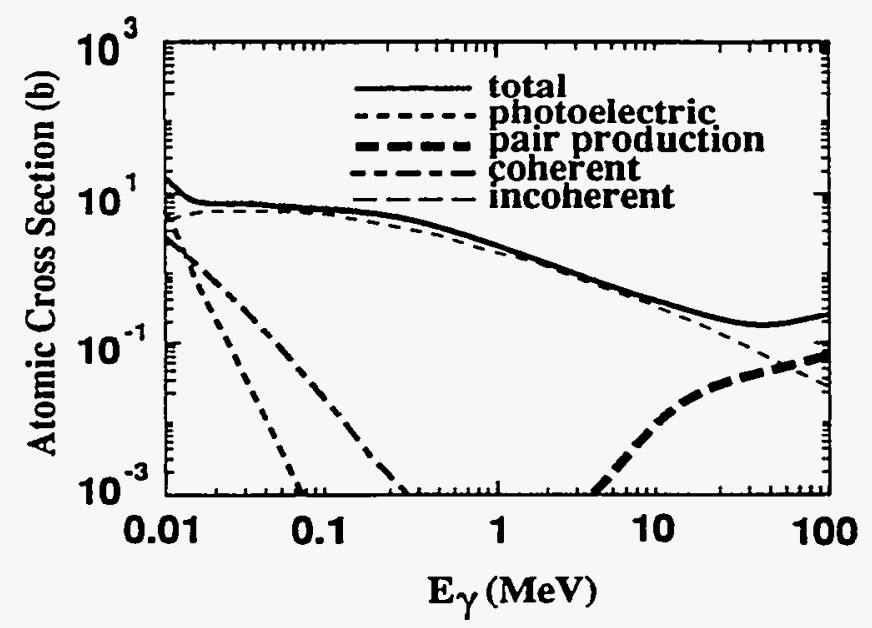

Figure 2: Cross section for atomic processes in $\mathrm{Li}$. (From [Ple78].)

\subsection{Numerical Values}

$\Phi_{e}$ : The number of electrons for an ampere-year,

$$
\Phi_{e}=1.97 \times 10^{26}
$$

$N_{7 L i}$ : The number of target atoms $N_{7 i}$ is estimated simply by multiplying the atom density of ${ }^{7} \mathrm{Li}$ $\left[\rho N_{0} / A=0.534 N_{0} / 7\right]$ by the target length $L$. The absorption processes for photons in $\mathrm{Li}$ are given in Fig. 2. Pair production is the only atomic mechanism for photon absorption in Li for photons in the energy range between 6 and $12 \mathrm{MeV}$, since photoelectric absorption is negligible, and the Compton process scatters photons with little energy loss and no absorption. The appropriate length for $1 / e \mathrm{ab}-$ sorption is $1 / \mu_{\text {pair. }}$. The interpolated value of $\mu_{\text {pair }}=4.08 \times 10^{-2} \mathrm{~b}$ at $9 \mathrm{MeV}$ [Ple78], and therefore $L=10.7 \mathrm{~m}$. Therefore,

$$
N_{7 i}=L \times \rho N_{0} / A=81.5 \times N_{0}
$$

$\sigma_{T}$ : Skopik, et al., [Sko79] have measured the differential cross section $\sigma_{T}$ at $\theta_{\gamma}=90^{\circ}$ for $6<$ $E_{\gamma}(\mathrm{MeV})<50$, and the total cross section over a much narrower range, $6<E_{\gamma}(\mathrm{MeV})<$ 15. The experimental results are illustrated in Fig. 3, (a) and (b) respectively.
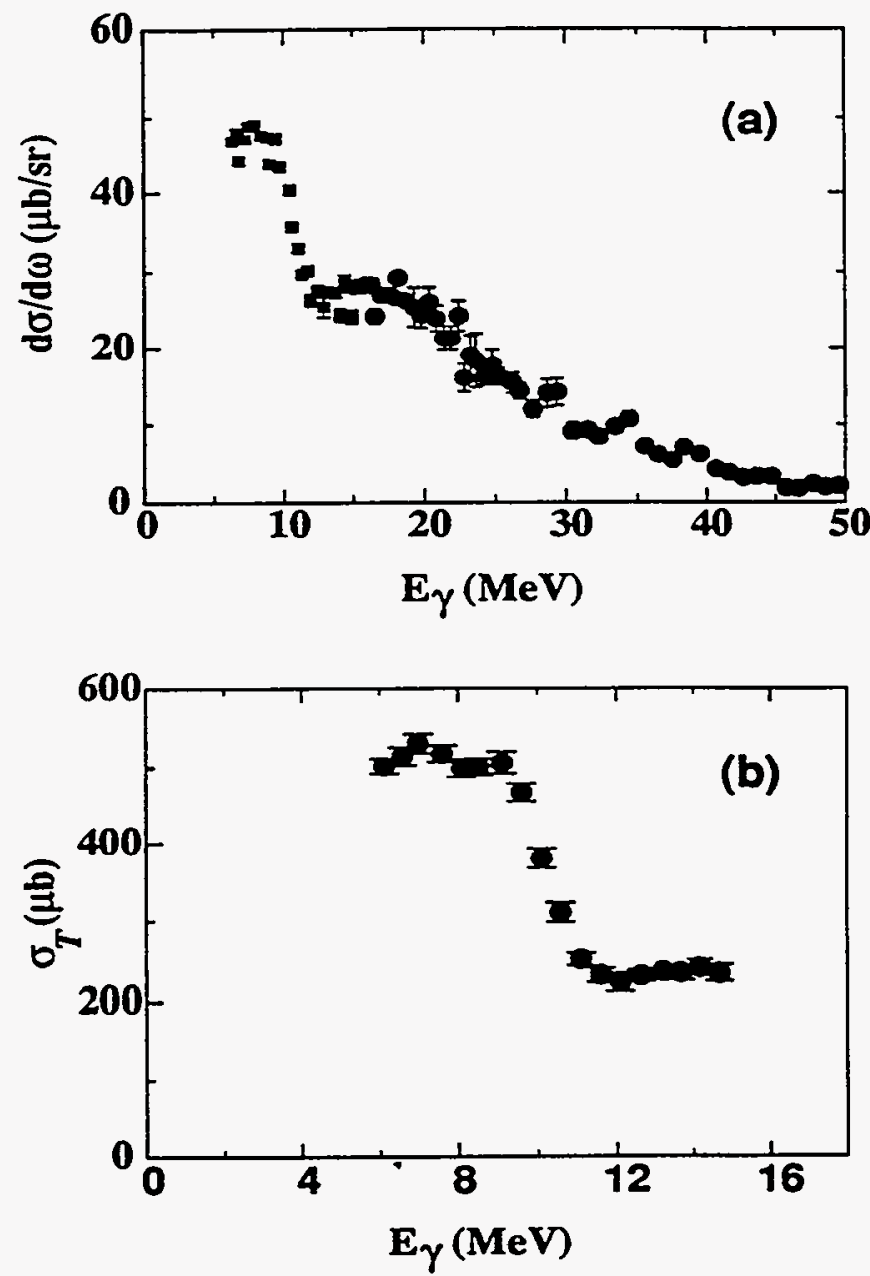

Figure 3: (a) The $90^{\circ}$ cross section for the ${ }^{7} \operatorname{Li}(\gamma, t)=$ and $(\gamma, \alpha) \bullet$ reactions. (b) The total cross section for the ${ }^{7} L i(\gamma, t)$ reaction for $E_{\gamma}$ between 6 and $15 \mathrm{MeV}$. (From [Sko79].)

The data show a resonance at $E_{\gamma}=7 \mathrm{MeV}$, with a width $\approx 7 \mathrm{MeV}$, and a smaller broad resonance around $E_{\gamma}=18 \mathrm{MeV}$. These data suggest $12 \mathrm{MeV}$ as a first cut for the incident electron energy. The integral of the total cross section estimated from Fig. $3 \mathrm{~b}$ between $E_{\gamma}=$ 6 and $12 \mathrm{MeV}$ is

$$
\sigma_{T}=2550 \mathrm{MeV} \mu \mathrm{b} /(6 \mathrm{MeV})=425 \mu \mathrm{b}
$$

The product of the three items gives:

$$
N_{T}^{\prime}=11.34 \times N_{0}=34.0 \mathrm{~g} /(\mathrm{a} \mathrm{y}) .
$$

This value must be corrected for the efficiency with which the accelerated electrons produce 
bremsstrahlung ( $\left.\epsilon_{b r e m s}\right)$ and the fraction of the bremsstrahlung photons that undergoes a nuclear reaction in the ${ }^{7} \mathrm{Li}$ assembly $\left(\epsilon_{\gamma}\right)$. Estimating $\epsilon_{b r e m s}=$ 0.75 and $\epsilon_{\gamma}=0.5$,

$$
N_{T}=N_{T}^{\prime} \times \epsilon_{\text {brems }} \times \epsilon_{\gamma}=12.8 \mathrm{~g} /(\mathrm{a} \mathrm{y}) .
$$

The main operating cost in accelerator based ${ }^{3} \mathrm{H}$ production is the cost of electrical energy. Therefore the significant figure-of-merit for comparison with APT is ${ }^{3} \mathrm{H}$ production in grams per MegaWatt-year, or $\mathrm{g} /(\mathrm{MW} y)$, assuming unit accelerator efficiency and unit ${ }^{3} \mathrm{H}$ recovery. Thus,

$$
\begin{array}{r}
N_{T}=N_{T} /\left(E_{e} \times i\right)=12.8 /(12 \mathrm{MeV} \times 1 \mathrm{a}) \\
=1.06 \mathrm{~g} /(\mathrm{MW} \mathrm{y}) .
\end{array}
$$

\section{Discussion of parameters}

Conservative values were used in the estimate of $N_{T}$ in section 4 . Very simple steps can greatly increase $N_{T}$.

1. The choice of electron incident energy is not optimized. Although the cross section $\sigma_{T}$ falls $\approx$ a factor of 2 between 10 and $12 \mathrm{MeV}$ (See Fig. 3), an incident election bombardment energy $E_{e}=12 \mathrm{MeV}$ was assumed and the cross section averaged for $E_{\gamma}$ between 6 and $12 \mathrm{MeV}$.

2. ${ }^{3} \mathrm{H}$ reaction cross section below $E_{\gamma}=6 \mathrm{MeV}$ is not used in the estimate of the integrated cross section, even though $\sigma_{T}$ is still maximum at 6 $\mathrm{MeV}$. The low energy cross section has not been measured, and Fig. 3 suggests that there is significant integrated cross section below $E_{\gamma}=6$ $\mathrm{MeV}$.

3. The target length used is $1 \times \mu_{\text {pair. }}^{-1}$. Doubling the target length increases ${ }^{3} \mathrm{H}$ production by $37 \%$, or $1 e$-fold. $\mu_{\text {pair }}$ was evaluated at $E_{\gamma}=9$ $\mathrm{MeV}$. It is dropping logarithmically with $E_{\gamma}$ and therefore the estimate of $\mathrm{L}$ is unrealistically low.

4. Reclamation of waste heat and electricity generation with $30 \%$ efficiency increases electrical efficiency by $43 \%$.
The last two items in the list are straight forward, and including them in the calculation increases $N_{T}$ substantially, from 1.06 to

$$
\begin{array}{r}
N_{T}(P P T)=1.06 \times(1+0.37) \times(1+0.43) \\
=2.08 \mathrm{~g} /(\mathrm{MW} \mathrm{y}) .
\end{array}
$$

The corresponding number for APT is (Appendix A.):

$$
N_{T}(A P T)=29.5 \mathrm{~g} /(\mathrm{MW} \mathrm{y}) .
$$

PPT is therefore a small but appreciable fraction of $\mathrm{APT}: \approx 7 \%$.

\section{Advantages of photoproduction of tritium (PPT)}

Photoproduction of ${ }^{3} \mathrm{H}$ as schematically outlined above has several advantages:

- negligible residual radioactivity

- simple target technology

- small low-energy electron accelerators for bremsstrahlung production

- modularity (spreading Risk)

- liquid metal technology developed for breeder reactors

- simple ${ }^{3} \mathrm{H}$ extraction from a recirculating ${ }^{7} \mathrm{Li}$ target

- abundant supply of ${ }^{7} \mathrm{Li}$

- straight forward interface of accelerator-targetbremsstrahlung

- waste heat recovery for direct generation of electricity

\section{Proposal}

Scenarios exist where PPT may be attractive. The production efficiency given in section 4 is an appreciable fraction of the APT figure-of-merit given here. We propose a program to investigate the potential of ${ }^{3} \mathrm{H}$ production by photodisintegration of ${ }^{7} \mathrm{Li}$. The first steps include: 
1. Experiments to measure total ${ }^{3} \mathrm{H}$ production as a function of incident electron energy.

2. Detailed transport calculations which include the relevant cross sections and their angular dependence. Optimal choice are required for bombardment energy and bremsstrahlung converter thickness. The choice of incident electron energy may have a strong effect on accelerator design.

3. Inventory of radioactive products in PPT.

4. Engineering studies of the heat recovery and electricity generation.

5. Detailed accelerator design, emphasizing reliability and current capacity.

This work was supported in part by U.S. Department of Energy, under Contract No. W7405-ENG-48.

\section{A APT in $\mathrm{g} /(\mathrm{MW} \mathrm{y})$}

Reasonable parameters are assumed for APT in order to arrive at a estimate of the ${ }^{3} \mathrm{H}$ production in grams/MegaWatt-year. Assume:

- a $1 \mathrm{GeV}$ proton accelerator

- a current of 0.1 a for $1 \mathrm{y}$

- $\mathrm{n} / \mathrm{p}$ conversion $=30$

- unit efficiency for $\mathbf{n}$ to ${ }^{3} \mathrm{H}$ conversion

The APT accelerator will produce

$$
\begin{array}{r}
N_{T}=1.97 \times 10^{25} \times 30 / N_{0}=981 \times N_{0} \\
=2.95 \times 10^{3} \mathrm{~g} / \mathrm{y},
\end{array}
$$

or,

$$
\begin{array}{r}
N_{T} /\left(E_{p} \times i\right)=2.95 \times 10^{3} /(1 \mathrm{GeV} \times 0.1 \mathrm{a}) \\
=29.5 \mathrm{~g} /(\mathrm{MW} \mathrm{y}) .
\end{array}
$$

\section{B Output per accelerator}

A reasonable $\mathrm{CW}$ electron current design goal is 0.5 a. The ${ }^{3} \mathrm{H}$ output per accelerator is $2.08 \times 0.5=$ $1.04 \mathrm{~g} / \mathrm{y}$, with the assumptions of Section 4. Accelerator farms are required to meet National Defense requirements. There is no inherent disadvantage to this, and there may well be advantages.

\section{Residual Radioactivity}

The conceptual arrangement proposed here produces very little residual radiation. Choice of a $\mathrm{Ta}$ bremsstrahlung target means the ${ }^{181} \mathrm{Ta}(\gamma, n)$ reaction $(Q=-7.57 \mathrm{MeV})$ in the converter will produce $8 \mathrm{~h}{ }^{180} \mathrm{Ta}$ nuclei. Natural Ta is essentially monoisotopic, $>99.98 \%{ }^{181} \mathrm{Ta}$. ${ }^{180} \mathrm{Ta}$ decays to a stable product. The $\gamma, n$ reaction in the ${ }^{7} \mathrm{Li}$ target is just at the threshold energy $(Q=-2.46 \mathrm{MeV})$. Therefore, neutron production in the ${ }^{7} \mathrm{Li}$ assembly will be small, and the reaction product ${ }^{6} \mathrm{Li}$ is stable. The main impurities are expected to be ${ }^{12} \mathrm{C}$ and ${ }^{16} \mathrm{O}$. The $\gamma, n$ reaction on these elements has $Q$ values of -18.72 and $-15.66 \mathrm{MeV}$, respectively, and so produces no residual radioactivity. The main background is expected to be at the ${ }^{7} \mathrm{Li}$ container walls.

\section{References}

[And95] Invention Case No.: II-9703. J. D. Anderson, J. A. Becker, and M. S. Weiss, Patent in process, 1995.

[Sko79] D. M. Skopik, J. Asai, E. L. Tomusiak, and J. J. Murphy II, Physical Review C 20, 2025 (1979).

[Ple78] E. F. Plechaty, D. E. Cullen, and R. J. Howerton UCRL-50400, V. 6, 1978 (unpublished). 